06

\title{
Роль карбида кремния в электродуговом синтезе высших фуллеренов
}

\author{
(C) И.Е. Кареев, ${ }^{1}$ А.Е. Дутлов, ${ }^{2}$ В.П. Бубнов ${ }^{1}$ \\ ${ }^{1}$ Институт проблем химической физики РАН, \\ 142432 Черноголовка, Россия \\ ${ }^{2}$ Московский государственный университет им. М.В. Ломоносова, \\ 119991 Москва, Россия \\ e-mail: kareev@icp.ac.ru
}

Поступило в Редакцию 25 марта 2019 г.

В окончательной редакции 17 апреля 2019 г.

Принято к публикации 21 июля 2019 г.

Исследовано влияние атомов кремния в зоне графитовой электрической дуги на эффективность образования высших фуллеренов $\mathrm{C}_{76}, \mathrm{C}_{78}, \mathrm{C}_{80}, \mathrm{C}_{82}, \mathrm{C}_{84}, \mathrm{C}_{86}$ и др. Добавки карбида кремния от 0 до $6.3 \mathrm{wt} . \%$ в композитные графитовые электроды и оптимизация условий их испарения позволяют получать сажу с содержанием высших фуллеренов до $15.5 \mathrm{wt} . \%$ в экстракте одновременно с высоким общим выходом фуллеренов $10.5 \%$ от веса сажи.

Ключевые слова: фуллерены, высшие фуллерены, карбид кремния, электродуговой синтез, ВЭЖХ.

DOI: $10.21883 /$ JTF.2020.01.48670.108-19

\section{Введение}

В электродуговом синтезе при испарении графитовых электродов наряду с основными компонентами, фуллеренами $\mathrm{C}_{60}$ и $\mathrm{C}_{70}$, образуются, хотя и в существенно меньших количествах, высшие фуллерены $\mathrm{C}_{76}$, $\mathrm{C}_{78}, \mathrm{C}_{84}, \mathrm{C}_{86}, \mathrm{C}_{90}$ и др. Эффективный электродуговой метод синтеза фуллеренов, предложенный В. Крэчмером и Д. Хаффманом [1], позволил синтезировать высшие фуллерены и приступить к исследованию их химикофизических свойств. Вскоре было установлено [2], что содержание высших фуллеренов в саже низкое и не превышает 2-3 wt.\% в экстрактах. Низкое содержание [3], трудоемкий метод выделения индивидуальных продуктов и большое число изомеров высших фуллеренов [4], которое растет с увеличением атомов углерода в молекуле, делает их дорогостоящими объектами [5]. Чистые высшие фуллерены, хотя и являются коммерческим продуктом, но из-за высокой стоимости (1 mg фуллерена $\mathrm{C}_{76}$ стоит несколько сотен долларов) недоступны для широкого круга исследователей. Несмотря на трудности выделения в чистом виде, высшие фуллерены интересны с научной точки зрения в плане изучения их физических свойств [6], строения [7] и реакционной способности [8-11].

Анализ литературных данных показал, что известные вариации метода электродугового синтеза сажи, позволяющие увеличить содержание высших фуллеренов, в основном связаны с использованием в синтезе композитных графитовых электродов с различными добавками. В работе [12] показано, что для повышения содержания в саже высших фуллеренов используют композитные электроды с добавками $\mathrm{B}, \mathrm{B}_{4} \mathrm{C}, \mathrm{Al}_{2} \mathrm{O}_{3}$, $\mathrm{Si}$. Однако результаты по выходу высших фуллеренов вызывают сомнения в правильности оценки содержания высших фуллеренов в экстрактах, выполненных по данным масс спектрометрии лазерной десорбции/ионизации. Из-за различной ионизационной способности фуллеренов такой подход не может быть количественным методом оценки состава экстрактов. Кроме того, использование добавок в графитовые электроды в этой работе привело к снижению почти в 2 раза общего выхода фуллеренов. В работе [13] исследовалось влияние на выход высших фуллеренов добавок бора в графитовый электрод. Оценка содержания высших фуллеренов в пиридиновом экстракте в этой работе рассчитывалась из отношения интегральной суммы площадей высших фуллеренов $\left(\mathrm{C}_{76}-\mathrm{C}_{96}\right)$ к интегралу всех фуллеренов, включая $\mathrm{C}_{60}$ и $\mathrm{C}_{70}$, которое составило до $40 \%$ при добавках $1 \mathrm{wt.} \%$ бора в электрод. Эти результаты явно завышены, поскольку не учитывают различие молярных коэффициентов экстинкций фуллеренов и высших фуллеренов. Ошибка обусловлена тем, что коэффициенты экстинкции фуллеренов $\mathrm{C}_{60}$ и $\mathrm{C}_{70}$ существенно меньше $\left(\varepsilon_{310 \mathrm{~mm}}=18900 \mathrm{M}^{-1} \mathrm{~cm}^{-1}\right.$ для $\mathrm{C}_{60}$ и $\varepsilon_{310 \mathrm{~nm}}=29500 \mathrm{M}^{-1} \mathrm{~cm}^{-1}$ для $\mathrm{C}_{70}$ ), чем суммарный коэффициент экстинкции высших фуллеренов $\left(\mathrm{C}_{76}-\mathrm{C}_{86}\right)$ на этой же длине волны хроматографа $\left(\varepsilon_{310 \mathrm{~nm}}=58500 \mathrm{M}^{-1} \mathrm{~cm}^{-1}\right)$ [14]. Поэтому полученный результат по выходу высших фуллеренов в этой работе с учетом коэффициентов экстинкции должен быть в $\sim 3$ раза меньше. Компаундирование электродов различными добавками, влияние соотношения буферного газа в виде смеси гелия и азота было проанализировано в работе [15]. Однако выход высших фуллеренов в саже определен по масс-спектрам и не может считаться корректным из-за различной ионизационной способности высших фуллеренов и фуллеренов $\mathrm{C}_{60}$ и $\mathrm{C}_{70}$. 
В последнее время развивается метод плазмохимического синтеза фуллеренов в высокочастотном разряде [16,17]. В [16] продемонстрирована возможность увеличения содержания высших фуллеренов в ВЧ-разряде путем повышения давления гелия от $1.0 \cdot 10^{5}$ до $3.8 \cdot 10^{5} \mathrm{~Pa}$. Анализ данных высокоэффективной жидкостной хроматографии (ВЭЖХ), представленных в этой работе, по методике [14] с учетом молярных коэффициентов экстинкций фуллеренов показал, что суммарное содержание высших фуллеренов $\left(\mathrm{C}_{76}-\mathrm{C}_{86}\right)$ в фуллереновой смеси не превышает $7 \mathrm{wt} . \%$ (давление гелия $3.8 \cdot 10^{5} \mathrm{~Pa}$ ), а общий выход фуллеренов составил 7 wt.\%. Можно отметить, что плазмохимический метод не показывает выдающихся результатов по синтезу сажи с высоким содержанием высших фуллеренов.

Наиболее достоверные результаты по содержанию высших фуллеренов при испарении композитных электродов, допированных карбонатом калия, приведены в нашей работе [18], в которой выход высших фуллеренов оценен с учетом коэффициентов молярной экстинкции всех фуллеренов. В работе показано, что введение добавок карбоната калия (3wt.\%) в графитовые электроды позволяет повысить более чем в 3 раза содержание (11.4 wt.\%) высших фуллеренов в экстракте по сравнению с использованием чистых графитовых электродов.

Также заслуживают особого внимания наши результаты по повышению содержания высших фуллеренов при использовании чистых графитовых электродов в „параллельной“ дуге [19]. При одновременном испарении двух электродов в электродуговом реакторе содержание высших фуллеренов в экстракте сажи достигает $13.8 \mathrm{wt} . \%$ и сравнимо с результатом, полученным при испарении композитных графитовых электродов с добавками карбоната калия [18].

В настоящей работе впервые исследовано влияние добавок карбида кремния в графитовый электрод на выход высших фуллеренов в синтезируемой саже. Оценка содержания высших фуллеренов в экстрактах проведена с учетом экспериментально установленных коэффициентов экстинкции фуллеренов $\mathrm{C}_{60}, \mathrm{C}_{70}$ и высших фуллеренов.

\section{Экспериментальная часть}

Синтез сажи с высоким содержанием высших фуллеренов проведен в электродуговом реакторе, подробно описанном нами в [20,21]. Сажу получали путем испарения композитных графитовых электродов, допированных карбидом кремния. Карбид кремния обладает высокой устойчивостью к температурному воздействию и разлагается при температуре $2830^{\circ} \mathrm{C}$ [22]. В электрической дуге при температуре $\sim 3500^{\circ} \mathrm{C}$ это соединение распадается на углерод и кремний. Если углерод, в силу испарения графитового электрода, уже присутствует в электродуговом пространстве и мало влияет на условия конденсации фуллеренов, то кремний в электродуговом пространстве оказывает существенное влияние и увеличивает скорость конденсации фуллеренов.

Для приготовления композитных электродов в графитовом стержне диаметром $6 \mathrm{~mm}$ и длиной $150 \mathrm{~mm}$ с двух сторон по центру высверливали отверстие Ø2.9 mm. Карбид кремния смешивали с графитовой пудрой и графитовым цементом марки „GC“ (Dylon Industries Inc.), используемого в качестве связующего. Весовые соотношения компонентов шихты приведены в табл. 1. Приготовленную шихту тщательно перемешивали и заполняли ею отверстие графитового стержня. Модифицированные таким образом графитовые стержни затем подвергали термообработке в три стадии:

1) обработка в вакуумной печи $\left(\sim 10^{-1} \mathrm{~Pa}\right)$ в течение $4 \mathrm{~h}$ при температуре $130^{\circ} \mathrm{C}$; при этой температуре происходит затвердевание графитового цемента, после этого стержень можно нагревать до высоких температур (вплоть до $3000^{\circ} \mathrm{C}$ ), не боясь его разрушения;

2) термообработка при $1000^{\circ} \mathrm{C}$ в течение $4 \mathrm{~h}$ в вакууме $\left(\sim 10^{-1} \mathrm{~Pa}\right)$, эта стадия необходима для превращения связующего, входящего в графитовый цемент, в углерод;

3) термообработка непосредственно в электродуговом реакторе в вакууме $\left(10^{-1} \mathrm{~Pa}\right)$ в течение $20 \mathrm{~min}$ при температуре $1800-1900^{\circ} \mathrm{C}$. Необходимая температура достигалась пропусканием через электрод постоянного электрического тока $180 \mathrm{~A}$.

Последняя термообработка не приводит к разложению карбида кремния в композитных электродах, но при этом электроды практически полностью очищаются от кислорода и других газов, адсорбированных в порах стержня, что способствует более стабильному горению дуги и приводит к увеличению содержания фуллеренов в синтезируемой саже. Атомарное содержание кремния в композитных электродах после термообработки составляло $0.25,0.5,0.8,1.0$ и $2.0 \%$.

Наряду с использованием новых подходов электродугового синтеза сажи с высоким содержанием высших фуллеренов, принципиально важным является вопрос их полного выделения из сажи. Выбор растворителя для экстракции высших фуллеренов важен и позволяет оптимизировать условия синтеза сажи. Для экстракции фуллеренов $\mathrm{C}_{60}, \mathrm{C}_{70}, \mathrm{C}_{76}-\mathrm{C}_{86}$ и др. опробованы растворители: толуол, $o$-ксилол и $о$-дихлорбензол (o-ДХБ). Последний показал высокую экстракционную эффективность полного выделения всех фуллеренов из сажи. Экстракцию фуллеренов проводили по следующей схеме. Навеску сажи 2-3 g загружали в экстракционный стаканчик из целлюлозы (Cellulose extraction thimbles, Whatman Int. Ltd.) и помещали в стеклянную колбу, содержащую 0.51 о-ДХБ ( $\geq 99 \%$ (GC), Sigma-Aldrich). Экстракцию проводили в течение 3-4h в атмосфере аргона при температуре кипения растворителя $\left(178^{\circ} \mathrm{C}\right)$. Затем раствор фуллеренов фильтровали (0.5 $\mu \mathrm{PTFE,}$ Phenomenex Filter Membranes) и концентрировали, отгоняя растворитель на роторном испарителе. Экстракцию 
Таблица 1. Содержание $\mathrm{Si}$ и $\mathrm{SiC}$ в термообработанных композитных электродах и состав шихты для их приготовления

\begin{tabular}{c|c|c|c|c|c}
\hline $\begin{array}{c}\text { Содержание } \\
\mathrm{SiC} \mathrm{в} \\
\text { графитовом } \\
\text { электроде, } \\
\text { t.\% }\end{array}$ & $\begin{array}{c}\text { Содержание } \\
\mathrm{Si} \mathrm{в} \\
\text { графитовом } \\
\text { электроде, } \\
\text { at.\% }\end{array}$ & $\begin{array}{c}\mathrm{Bec} \\
\text { графитового } \\
\text { электрода, } \\
\mathrm{g}\end{array}$ & $\begin{array}{c}\text { Вес } \\
\text { карбида } \\
\text { кремния, } \\
\mathrm{g}\end{array}$ & $\begin{array}{c}\text { Вес } \\
\text { графитовой } \\
\text { пудры, } \\
\mathrm{g}\end{array}$ & $\begin{array}{c}\text { Вес } \\
\text { графитового } \\
\text { цемента, } \\
\mathrm{g}\end{array}$ \\
\hline 0.8 & 0.25 & 5.0 & 0.06 & 0.6 & 1.0 \\
1.6 & 0.5 & 5.1 & 0.10 & 0.5 & 1.0 \\
3.5 & 0.8 & 5.0 & 0.16 & 0.5 & 1.0 \\
6.3 & 1.0 & 5.1 & 0.21 & 0.5 & 1.0 \\
\end{tabular}

Примечани е : * указано содержание компонентов после термообработки электродов.

продолжали до тех пор (обычно 2-3 цикла), пока свежая порция растворителя практически не окрашивалась. Фуллереновый экстракт выделяли из о-ДХБ высаливанием диэтиловым эфиром, отфильтровывали на фильтре с тефлоновым покрытием (0.5 $\mu$ PTFE, Phenomenex Filter Membranes), промывали диэтиловым эфиром и высушивали в вакууме. Полученный образец собирали, взвешивали и определяли выход фуллеренового экстракта от веса сажи.

Анализ состава фуллереновых экстрактов проводили методом ВЭЖХ на колонке Cosmosil Buckyprep $(10 \times 250 \mathrm{~mm})$. В качестве элюента использовали толуол, длина волны УФ-детектора составляла $310 \mathrm{~nm}$. Поведение фуллеренового экстракта на колонке Cosmosil Buckyprep к настоящему времени хорошо изучено, что позволяет соотносить пики на хроматограмме с индивидуальными молекулами фуллеренов и их изомеров без привлечения масс спектрометрии [23,24]. Содержание фуллеренов $\mathrm{C}_{76}, \mathrm{C}_{78}, \mathrm{C}_{80}, \mathrm{C}_{82}, \mathrm{C}_{84}, \mathrm{C}_{86}$ в экстракте оценивалось по ВЭЖХ хроматограммам путем интегрирования пиков отдельных компонентов с учетом молярных коэффициентов экстинкции фуллеренов $\mathrm{C}_{60} \quad\left(\varepsilon_{310 \mathrm{~nm}}=18900 \mathrm{M}^{-1} \mathrm{~cm}^{-1}\right), \mathrm{C}_{70}$ $\left(\varepsilon_{310 \mathrm{~nm}}=29500 \mathrm{M}^{-1} \mathrm{~cm}^{-1}\right)$ и суммарного молярного коэффициента экстинкции высших фуллеренов $\mathrm{C}_{76}, \mathrm{C}_{78}$, $\mathrm{C}_{80}, \mathrm{C}_{82}, \mathrm{C}_{84}, \mathrm{C}_{86}\left(\varepsilon_{310 \mathrm{~nm}}=58500 \mathrm{M}^{-1} \mathrm{~cm}^{-1}\right)$ [14]. А количество фуллеренов $\mathrm{C}_{88}, \mathrm{C}_{90}, \mathrm{C}_{92}, \mathrm{C}_{94}, \mathrm{C}_{96}$ и др. рассчитывалось, как было показано в [15], из условия, что они составляют $1 / 3$ от суммарного содержания всех высших фуллеренов в экстракте.

\section{Обсуждение результатов}

В результате электродугового испарения композитных графитовых электродов с различным содержанием карбида кремния получены сажи, содержащие фуллерены $\mathrm{C}_{60}, \mathrm{C}_{70}$ и высшие фуллерены $\left(\mathrm{C}_{76}, \mathrm{C}_{78}, \mathrm{C}_{84}, \mathrm{C}_{86}\right.$ и др.). Сажи получены в условиях оптимального испарения композитных электродов при неизменной полярности между катодом и анодом. В условиях оптимального испарения композитных электродов визуально наблюдается яркое свечение и из зоны дуги истекает углеродный

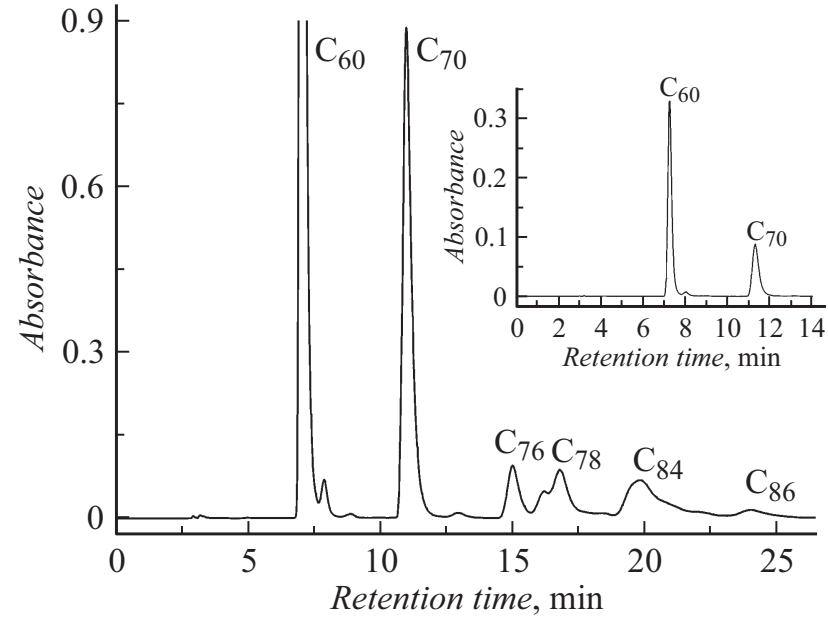

ВЭЖХ хроматограмма $о$-ДХБ экстракта фуллеренсодержащей сажи на колонке Cosmosil Buckyprep, инжекция образца $20 \mu \mathrm{L}$, скорость элюента $4.5 \mathrm{~mL} / \mathrm{min}$, элюент - толуол, длина волны детектирования $310 \mathrm{~nm}$, температура колонки $30^{\circ} \mathrm{C}$. На вставке - хроматограмма образца, разбавленного 10 раз.

пар белого цвета, т.е. в дуге достигнута необходимая температура, при которой твердый графит и карбид кремния расплавляются, превращаются в жидкость, закипают и испаряются. Отклонение от оптимальных условий, например, при токе дуги, превышающем оптимальный, приводит к изменению цвета пара на коричневый, а при токе меньше оптимального электрод не испаряется и пар отсутствует.

Количественный анализ смесей фуллеренов, полученных после экстракции саж о-ДХБ, проводили методом ВЭЖХ с учетом коэффициентов экстинкции фуллеренов $\mathrm{C}_{60}, \mathrm{C}_{70}$ и среднего сумарного коэффициента экстинкции высших фуллеренов $\mathrm{C}_{76}-\mathrm{C}_{86}$. На рисунке представлена общая хроматограмма $о$-ДХБ экстракта фуллеренсодержащей сажи, на которой два первых пика соответствуют фуллеренам $\mathrm{C}_{60}$ и $\mathrm{C}_{70}$. На рисунке (вставка) показана хроматограмма того же образца $о$-ДХБ экстракта, разбавленного в 10 раз, для определения соотношения между фуллеренами $\mathrm{C}_{60}$ и $\mathrm{C}_{70}$ и последующего вычисления содержания компонентов смеси фуллеренов. 
Таблица 2. Выход фуллеренового экстракта и его состав, полученный при различных добавках кремния

\begin{tabular}{|c|c|c|c|c|c|c|}
\hline \multirow{2}{*}{$\begin{array}{c}\text { Содержание } \mathrm{Si} \text { в } \\
\text { графитовом } \\
\text { электроде, } \\
\text { at.\% }\end{array}$} & \multirow{2}{*}{$\begin{array}{c}\text { Давление } \\
\text { гелия } \\
10^{4} \mathrm{~Pa}\end{array}$} & \multirow{2}{*}{$\begin{array}{c}\text { Выход } \\
\text { фуллеренов } \\
\text { от веса сажи } \\
\text { \% }\end{array}$} & \multicolumn{4}{|c|}{ Состав экстракта, wt.\% } \\
\hline & & & $\mathrm{C}_{60}$ & $\mathrm{C}_{70}$ & $\mathrm{C}_{76}-\mathrm{C}_{86}$ & $\sum \mathrm{C}_{2 n}$ \\
\hline 0 & 1.2 & 10 & 85.0 & 11.9 & 2.1 & 3.1 \\
\hline 0 & 2.0 & 11 & 67.4 & 21.4 & 7.5 & 11.2 \\
\hline 0.25 & 2.0 & 7.7 & 66.7 & 21.3 & 8.3 & 12.0 \\
\hline 0.5 & 2.0 & 10.5 & 62.3 & 22.2 & 10.3 & 15.5 \\
\hline 0.8 & 2.0 & 7.7 & 64.1 & 22.0 & 9.2 & 13.9 \\
\hline 1.0 & 2.0 & 9.0 & 64.2 & 21.1 & 9.8 & 14.7 \\
\hline 2.0 & 2.0 & 4.8 & 66.8 & 21.7 & 7.7 & 11.5 \\
\hline
\end{tabular}

Примечание: * $\sum \mathrm{C}_{2 n}-$ смесь высших фуллеренов $\mathrm{C}_{76}, \mathrm{C}_{78}, \mathrm{C}_{80}, \mathrm{C}_{82}, \mathrm{C}_{84}, \mathrm{C}_{86}, \mathrm{C}_{88}, \mathrm{C}_{90}$ и др.

В табл. 2 представлены результаты по влиянию кремния на общий выход фуллеренов и высших фуллеренов $\left(\mathrm{C}_{76}, \mathrm{C}_{78}, \mathrm{C}_{80}, \mathrm{C}_{82}, \mathrm{C}_{84}, \mathrm{C}_{86}\right.$ и др.) при испарении композитных графитовых электродов с различным содержанием карбида кремния. Из представленных в таблице данных видно, что выход высших фуллеренов при испарении композитных электродов с увеличением содержания кремния от 0 до 2 at.\% возрастает и достигает максимума $15.5 \%$ от веса экстракта при 0.5 at.\% кремния. При этом, что особенно важно, общее суммарное содержание всех фуллеренов, равное $10.5 \%$ от веса сажи, практически не изменилось по сравнению с испарением чистого графита. Одновременно можно видеть, что содержание в экстракте высших фуллеренов возрастает, а фуллерена $\mathrm{C}_{60}-$ уменьшается. Таким образом, при испарении композитных графитовых электродов присутствие в дуге атомов кремния способствует образованию высших фуллеренов, подавляет образование $\mathrm{C}_{60}$ и практически не влияет на содержание $\mathrm{C}_{70}$.

Увеличение или уменьшение давления гелия по отношению к оптимальному, экспериментально установленному в нашей работе [18] и равному $2.0 \cdot 10^{4} \mathrm{~Pa}$, приводит к уменьшению выхода высших фуллеренов. В случае испарения спектрально чистого графитового электрода при давлении гелия $1.2 \cdot 10^{4} \mathrm{~Pa}$ содержание высших фуллеренов в экстракте составляет всего $3.1 \mathrm{wt} \%$ и существенно меньше по сравнению с испарением композитных электродов, а суммарный выход всех фуллеренов, равный $10 \%$ от веса сажи, лишь незначительно отличается. В результате проведенных исследований экспериментально определены оптимальные параметры электродугового синтеза сажи с высоким содержанием высших фуллеренов (до 15.5 wt.\% в экстракте) и общим выходом фуллеренов 10.5 wt.\% [Si/графит (0.5 at.\%)]; давление гелия - $2 \cdot 10^{4} \mathrm{~Pa}$; напряжение на дуге $26 \mathrm{~V}$; ток дуги - $78 \mathrm{~A}$. Сопоставление результатов, достигнутых в настоящей работе, показало, что они превосходят ранее полученные нами в $[18,19]$ как по содержанию высших фуллеренов, так и по общему выходу фуллеренов.
Анализ полученных результатов показывает, что увеличение выхода высших фуллеренов при испарении допированных карбидом кремния композитных графитовых электродов можно объяснить повышением температуры в зоне дуги и присутствием в этой зоне атомов кремния, которые увеличивают скорость конденсации фуллеренов. Кроме того, установлено, что необходимая мощность для стабильного горения дуги при испарении композитных графитовых электродов в $\sim 1.5$ раза превышает мощность при испарении чистого графита. $\mathrm{B}$ результате возбужденные углеродные частицы $\mathrm{C}_{1}, \mathrm{C}_{2}$ и $\mathrm{C}_{3}$, на которые распадается графит, обладая большей энергией и соответственно большей скоростью, быстрее преодолевают зону с температурой конденсации фуллеренов $\mathrm{C}_{60}$ и $\mathrm{C}_{70}$ и достигают областей с более низкой температурой, где образуются высшие фуллерены. Чем выше энергия возбужденных углеродных частиц в зоне дуги, тем меньше образуется фуллерена $\mathrm{C}_{60}$ [25] и больше высших фуллеренов. Также чувствительным параметром к общему выходу фуллеренов и его составу является расстояние от дуги до охлаждаемой поверхности установки. С уменьшением расстояния возрастает градиент температуры и уменьшается время пролета углеродных частиц до зон, где формируются фуллерены. Эти выводы подтверждают результаты, полученные в работе [26], где показано, что при расстоянии от дуги до охлаждаемой поверхности, равном $1 \mathrm{~cm}$, фуллерены вообще не образуются, а при расстоянии $4 \mathrm{~cm}$ выход фуллеренов максимален. Экспериментальные результаты (см. табл. 1) подтверждают качественное объяснение механизма образования фуллеренов при испарении компаундированных электродов.

\section{Заключение}

В работе показано, что введение добавок карбида кремния в графитовые электроды позволяет повысить более чем в 5 раз содержание высших фуллеренов в синтезируемой саже по сравнению с использованием чистых графитовых электродов, расположенных в цен- 
тре электродуговой установки при давлении $1.2 \cdot 10^{4} \mathrm{~Pa}$. Эффективное образование высших фуллеренов можно объяснить присутствием в зоне дуги дополнительно атомов кремния и увеличением в 1.5 раза электрической мощности в дуге, требуемой для испарения композитных электродов. Экспериментально установлено оптимальное содержание кремния в композитном электроде, равное 0.5 at.\%, и давление гелия, равное $2 \cdot 10^{4} \mathrm{~Pa}$, при котором содержание высших фуллеренов в экстракте максимально и составляет 15.5 wt.\%.

\section{Финансирование работы}

Работа выполнена по теме Государственного задания, номер государственной регистрации 0089-2019-0011.

\section{Конфликт интересов}

Авторы заявляют, что у них нет конфликта интересов.

\section{Список литературы}

[1] Kratschmer W., Lamb L.D., Fostiropoulos K. Huffman D.R. // Nature. 1990. Vol. 347. N 6291. P. 354-358. DOI: https://doi.org/10.1038/347354a0

[2] Елеикий А.В., Смирнов Б.М. // УФН. 1995. Т. 165. Вып. 9. C. $977-1009$.

DOI: https://doi.org/10.3367/UFNr.0165.199509a.0977 [Eletskii A.V., Smirnov B.M. // Phys. Usp. 1995. Vol. 38. P. 935-964.]

[3] Sigma-Aldrich. $\mathbf{5 7 2 4 9 7}$ Aldrich. Fullerene soot (as produced) // URL: http://www.sigmaaldrich.com/catalog/pro$\mathrm{duct} /$ aldrich/572497? lang $=$ en\&region $=\mathrm{RU}$

[4] Fowler P.W., Manolopoulous D.E. An Atlas of Fullerens. Clarendon. Oxford, 1995. P. 392.

[5] Sigma-Aldrich. 482951 Aldrich. Fullerene-C 76 98\% // URL: http://www.sigmaaldrich.com/catalog/product/aldrich/482951? lang $=$ en\&region $=\mathrm{US}$

[6] Лобанов Б.В., Мурзашев А.И. // ФТТ. 2013. Т. 55. Вып. 4. C. 797-805. [Lobanov B.V., Murzashev A.I. // Phys. Solid State. 2013. Vol. 55. N 4. P. 868-877.

DOI: https://doi.org/10.1134/S1063783413040173]

[7] Sudarkova S.M., Mazaleva O.N., Konoplev-Esgenburg R.A., Troyanov S.I., Ioffe I.N. // Dalton Transactions. 2018. Vol. 47. N 13. P. 4554-4559. DOI: http://dx.doi.org/10.1039/c8dt00245b

[8] Tamm N.B., Troyanov S.I. // Mendeleev Communications. 2016. Vol. 26. N 4. P. 312-313. DOI: http://dx.doi.org/10.1016/j.mencom.2016.07.015

[9] Kosaya M.P., Fritz M.A., Brotsman V.A., Tamm N.B., Ignat'eva D.V., Troyanov S.I. // Chem. Asian J. 2016. Vol. 11. N 7. P. $1000-1003$. DOI: http://dx.doi.org/10.1002/asia.201600094

[10] Kareev I.E., Popov A.A., Kuvychko I.V., Shustova N.B., Lebedkin S.F., Bubnov V.P., Anderson O.P., Seppelt K., Strauss S.H., Boltalina O.V. // J. Am. Chem. Soc. 2008. Vol. 130. N 40. P. 13471-13489.

DOI: https://doi.org/10.1021/ja8041614

[11] Kareev I.E., Kuvychko I.V., Shustova N.B., Lebedkin S.F., Bubnov V.P., Anderson O.P., Popov A.A., Boltalina O.V., Strauss S.H. // Angew. Chem. Int. Ed. 2008. Vol. 47. N 33. P. 6204-6207. DOI: https://doi.org/10.1002/anie.200801777
[12] Tohji K., Paul A., Moro L., Malhotra R., Lorents D.C., Ruoff R.S. // J. Phys. Chem. 1995. Vol. 99. N 50. P. 17785-17788. DOI: https://doi.org/10.1021/j100050a018

[13] Kimura T., Sugai T., Shinohara H., Goto T., Tohji K., Matsuoka I. // Chem. Phys. Lett. 1995. Vol. 246. N 6. P. 571576. DOI: https://doi.org/10.1016/0009-2614(95)01174-2

[14] Кареев И.Е., Некрасов В.М., Бубнов В.П. // Изв. АН. Сер. хим. 2015. Вып. 2. С. 391-394. [Kareev I.E., Nekrasov V.M., Bubnov V.P. // Russ. Chem. Bull. 2015. Vol. 64. N 2. P. 391394. DOI: https://doi.org/10.1007/s11172-015-0874-x]

[15] Cao B.P., Zhou L.Q., Shi Z.J., Zhou X.H., Gu Z.N., Xiao H.Z., Wang J.Z. // Carbon. 1998. Vol. 36. N 4. P. 453-456. DOI: https://doi.org/10.1016/S0008-6223(97)00229-7

[16] Churilov G.N., Kratschmer W., Osipova I.V., Glushenko G.A., Vnukova N.G., Kolonenko A.L., Dudnik A.I. // Carbon. 2013. Vol. 62. P. 389-392.

DOI: http://dx.doi.org/10.1016/j.carbon.2013.06.022

[17] Чурилов Г.Н., Попов А.А., Внукова Н.Г., Дудник А.И., Глущенко Г.А., Самойлова Н.А., Дубинина И.А., Гуляева У.Е. // Письма в ЖТФ. 2016. Т. 42. Вып. 9. С. 6470. [Churilov G.N., Popov A.A., Vnukova N.G., Dudnik A.I., Glushchenko G.A., Samoylova N.A., Dubinina I.A., Gulyaeva U.E. // Tech. Phys. Lett. 2016. Vol. 42. N 5. P. 475 477. DOI: http://dx.doi.org/10.1134/S1063785016050072]

[18] Кареев И.Е., Некрасов В.М., Бубнов В.П. // ЖТФ. 2015. T. 85. Вып. 1. С. 104-108. [Kareev I.E., Nekrasov V.M., Bubnov V.P. // Tech. Phys. 2015. Vol. 60. N 1. P. 102-104. DOI: https://doi.org/10.1134/S1063784215010144]

[19] Дутлов А.Е., Некрасов В.М., Сергеев А.Г., Кареев И.Е., Бубнов В.П. // ЖТФ. 2016. Т. 86. Вып. 12. C. 99-103. DOI: https://doi.org/10.1134/S1063784216120100 [Dutlov A.E., Nekrasov V.M., Sergeev A.G., Kareev I.E., Bubnov V.P. // Tech. Phys. 2016. Vol. 61. N 12. P. 1856-1860. DOI: https://doi.org/10.21883/jtf.2016.12.43922.1644]

[20] Бубнов В.П., Краинский И.С., Лаухина Е.Э., Ягубский Э.Б. // Изв. АН. Сер. хим. 1994. Вып. 5. С. 805-809. [Bubnov V.P., Krainskii I.S., Laukhina E.E., Yagubskii E.B. // Russ. Chem. Bull. 1994. Vol. 43. N 5. P. 746-750. DOI: https://doi.org/10.1007/BF00717331]

[21] Кареев И.Е., Бубнов В.П., Федутин Д.Н. // ЖТФ. 2009. T. 79. Вып. 11. С. 134-137. [Kareev I.E., Bubnov V.P., Fedutin D.N. // Tech. Phys. 2009. Vol. 54. N 11. P. 1695-1698. DOI: https://doi.org/10.1134/S1063784209110231]

[22] Ефимов А.И., Белорукова Л.П., Василькова И.В., Чечев В.П. Свойства неорганических соединений / Под ред. В.А. Рабиновича. Л.: Химия, 1983. 144 с.

[23] Кареев И.Е., Бубнов В.П., Ягубский Э.Б. // Изв. АН. Сер. хим. 2007. Вып. 11. С. 2067-2071. [Kareev I.E., Bubnov V.P., Yagubskii E.B. // Russ. Chem. Bull. 2007. Vol. 56. N 11. P. $2140-2144$. DOI: https://doi.org/10.1007/s11172-007-0338-z]

[24] Richter H., Labrocca A.J., Grieco W.J., Taghizadeh K., Lafleur A.L., Howard J.B. // J. Phys. Chem. B. 1997. Vol. 101. N. 9. P. 1556-1560. DOI: https://doi.org/10.1021/jp962928c

[25] Алексеев Н.И., Дюжев Г.А. // ЖТФ. 2002. Т. 72. Вып. 5. C. 121-129. [Alekseev N.I., Dyuzhev G.A. // Tech. Phys. 2002. Vol. 47. N 5. P. 634-642. DOI: https://doi.org/10.1134/1.1479995]

[26] Каратаев В.И. // ФТТ. 1994. Т. 36. Вып. 9. С. 2795-2798. 